\title{
Should the CIWA-Ar be the standard monitoring strategy for alcohol withdrawal syndrome in the intensive care unit?
}

Tessa L. Steel ${ }^{1^{*}} \mathbb{0}$, Shewit P. Giovanni ${ }^{2}$, Sarah C. Katsandres ${ }^{3}$, Shawn M. Cohen ${ }^{4}$, Kevin B. Stephenson ${ }^{5}$, Ben Murray ${ }^{5}$, Hillary Sobeck ${ }^{6}$, Catherine L. Hough ${ }^{2}$, Katharine A. Bradley ${ }^{7}$ and Emily C. Williams ${ }^{1}$

\begin{abstract}
Background: The Clinical Institute Withdrawal Assessment for Alcohol-Revised (CIWA-Ar) is commonly used in hospitals to titrate medications for alcohol withdrawal syndrome (AWS), but may be difficult to apply to intensive care unit (ICU) patients who are too sick or otherwise unable to communicate.
\end{abstract}

Objectives: To evaluate the frequency of CIWA-Ar monitoring among ICU patients with AWS and variation in CIWAAr monitoring across patient demographic and clinical characteristics.

Methods: The study included all adults admitted to an ICU in 2017 after treatment for AWS in the Emergency Department of an academic hospital that standardly uses the CIWA-Ar to assess AWS severity and response to treatment. Demographic and clinical data, including Richmond Agitation-Sedation Scale (RASS) assessments (an alternative measure of agitation/sedation), were obtained via chart review. Associations between patient characteristics and CIWA-Ar monitoring were tested using logistic regression.

Results: After treatment for AWS, only 56\% ( $n=54 / 97)$ of ICU patients were evaluated using the CIWA-Ar; $94 \%$ of patients had a documented RASS assessment $(n=91 / 97)$. Patients were significantly less likely to receive CIWA-Ar monitoring if they were intubated or identified as Black.

Conclusions: CIWA-Ar monitoring was used inconsistently in ICU patients with AWS and completed less often in those who were intubated or identified as Black. These hypothesis-generating findings raise questions about the utility of the CIWA-Ar in ICU settings. Future studies should assess alternative measures for titrating AWS medications in the ICU that do not require verbal responses from patients and further explore the association of race with AWS monitoring.

Keywords: Alcohol-induced disorders, Nervous system, Critical care, Hypnotics and sedatives, Monitoring, physiologic, Drug monitoring, Quality of health care

\footnotetext{
*Correspondence: tessita@uw.edu

1 Seattle-Denver Center of Innovation (COIN), VA Puget Sound Health

Care System, Seattle Division, 1660 South Columbian Way S-152, SeattleSeattle, WA 98108, USA

Full list of author information is available at the end of the article
}

\begin{abstract}
Text
Alcohol withdrawal syndrome (AWS) is common in patients admitted to intensive care units (ICUs) and can be fatal without individualized treatment [1]. Clinical guidelines therefore recommend use of a standardized, scaled measure to guide management of AWS [2]. The most widely used measure is the Clinical Instrument Withdrawal Assessment for Alcohol-Revised
\end{abstract}

(C) The Author(s) 2021. This article is licensed under a Creative Commons Attribution 4.0 International License, which permits use, sharing, adaptation, distribution and reproduction in any medium or format, as long as you give appropriate credit to the original author(s) and the source, provide a link to the Creative Commons licence, and indicate if changes were made. The images or other third party material in this article are included in the article's Creative Commons licence, unless indicated otherwise in a credit line to the material. If material is not included in the article's Creative Commons licence and your intended use is not permitted by statutory regulation or exceeds the permitted use, you will need to obtain permission directly from the copyright holder. To view a copy of this licence, visit http://creativeco mmons.org/licenses/by/4.0/. The Creative Commons Public Domain Dedication waiver (http://creativecommons.org/publicdomain/ zero/1.0/) applies to the data made available in this article, unless otherwise stated in a credit line to the data. 
(CIWA-Ar), a 10-item scale based on patient interview and physical exam that showed clinical benefit in veterans admitted to a specialized detoxification unit with uncomplicated AWS [3, 4]. Studies in general hospital settings, however, show that $14-23 \%$ of patients in whom the CIWA-Ar is ordered cannot communicate and are not appropriate candidates for symptom-triggered therapy $[5,6]$. The feasibility of using such a scale in ICUs, where patients are critically ill, often sedated, and frequently unable to speak due to encephalopathy or intubation (placement of a "breathing tube" in a patient's upper airway to support breathing with a ventilator), has not been assessed. This study evaluated use of the CIWA-Ar in ICU patients with AWS at a hospital with a protocol specifying its use for assessment of AWS severity and response to treatment, and describes variation in CIWAAr monitoring across patient subgroups.

\section{Methods}

This retrospective cohort study was designed to evaluate AWS treatment monitoring in medical, trauma, and neurological ICU patients at a large academic hospital. Data were collected from electronic hospital sources via automated extraction and subsequent manual chart review. The study was approved by the University of Washington Institutional Review Board.

All patients treated for AWS in the Emergency Department (ED) prior to ICU admission in 2017 were included. The sample was limited to ICU patients treated for AWS in the ED (as opposed to all ICU patients with AWS) to standardize the timing of AWS treatment onset. AWS was defined by primary or secondary discharge international classification of diseases (ICD) diagnosis codes and confirmed via manual chart review. Treatment for AWS was defined by continuous infusion or multiple administrations of benzodiazepines, antiepileptics, antipsychotics, antisympathomimetics, propofol, and/or ethanol intended to treat AWS, determined by review of clinical notes and pharmacy data. At the study hospital, ED providers initiate treatment for AWS on a case-by-case basis, using clinical experience to recognize signs/symptoms of AWS (there is no standardized screening protocol). Communication of clinical concern for AWS occurs via verbal physician-to-physician pass-off between ED and ICU providers. ICU providers can also recognize ED treatment for AWS by reviewing documentation of events that transpire in the ED using the electronic health record.

CIWA-Ar scores (0-67 points) were categorized as $\leq 8$ mild, 9-19 moderate, and $\geq 20$ severe [3]. Sedation monitoring within $24 \mathrm{~h}$ of ICU admission using the Richmond Agitation-Sedation Scale (RASS) was also evaluated. The RASS is a 10-point scale ( -5 unarousable to +4 combative) assigned by nurses or other providers that is widely used in ICU settings [7]. In patients with a documented RASS assessment, agitation/sedation was categorized as optimal (RASS -2 to 0 ), oversedated (RASS -3 to -5 ), or undersedated (RASS +1 to +4 ) based on the Prevention and Management of Pain, Agitation/Sedation, Delirium, Immobility, and Sleep Disruption in Adult Patients in the ICU (PADIS) guidelines [8]. The PADIS guidelines are endorsed by all major international critical care societies and provide evidence-based recommendations regarding agitation/sedation goals. In ICUs at the study hospital, protocols for the CIWA-Ar (used specifically for AWS) and the RASS (used more generally for assessment of agitation/sedation) are triggered by a physician order. Nurses may decline to carry out the order for CIWA-Ar monitoring in patients who cannot respond to CIWA-Ar questions. While ICU nurses do not generally measure CIWA-Ar scores without a physician order, RASS assessments are sometimes performed at the discretion of ICU nurses without a physician order to document level of agitation/sedation. Admission severity of illness was determined by a proprietary algorithm used by the study hospital [i.e., $3 \mathrm{M}$ All Patients Refined Diagnosis Related Groups (APR-DRG) grouper], including age, sex, admission diagnosis, and secondary conditions.

The main outcome was presence or absence of CIWAAr assessment(s) within 24 h of ICU admission [3, 7]. Analyses evaluated the proportion of patients with CIWA-Ar assessment(s) overall and across demographic and clinical characteristics. Variables with a significant univariate association with CIWA-Ar assessment ( $\alpha$ set to 0.05 ) were further evaluated in a multivariable logistic regression model with adjustment for age, sex, race, intubation status (yes/no), and severity of illness, planned a priori. This was the first naturalistic evaluation of factors associated with CIWA-Ar monitoring in ICU patients. Given limited prior literature, predicting which variables would be most important to include in the multivariable model was challenging. We prioritized demographic characteristics and markers of illness severity (i.e., intubation status and the severity of illness APR-DRG grouper) a priori, then used univariate associations to guide inclusion of two additional patient characteristics: prior-year hospitalization with AWS and positive serum/urine alcohol level. Secondary analyses described AWS severity, as measured in patients with a documented CIWA-Ar assessment, and level of agitation/sedation, as measured in patients with a documented RASS assessment.

\section{Results}

Among ICU patients treated for AWS ( $\mathrm{n}=97)$, only $56 \%$ $(\mathrm{n}=54)$ were assessed with the CIWA-Ar within $24 \mathrm{~h}$ of admission (Table 1). Use of CIWA-Ar monitoring varied 
Table 1 Characteristics of intensive care unit (ICU) patients treated for alcohol withdrawal syndrome (AWS)

\begin{tabular}{|c|c|}
\hline & $\begin{array}{l}\text { All } \\
(n=97)\end{array}$ \\
\hline Age years, mean (sd) & $49.9(12.0)$ \\
\hline Male, no. (\%) & $79(81.4)$ \\
\hline \multicolumn{2}{|l|}{ Race, no. (\%) } \\
\hline American Indian/Alaska Native & $11(11.3)$ \\
\hline Black & $11(11.3)$ \\
\hline White & $70(72.2)$ \\
\hline Other & $5(5.2)$ \\
\hline Latino/Hispanic Ethnicity, no. (\%) & $11(11.3)$ \\
\hline Non-English primary language, no. (\%) & $7(7.2)$ \\
\hline Single, no. (\%) & $75(77.3)$ \\
\hline Homeless, no. (\%) & $26(26.8)$ \\
\hline \multicolumn{2}{|l|}{ Admission Severity of IIIness, no. (\%) } \\
\hline Extreme & $34(35.1)$ \\
\hline Major & $37(38.1)$ \\
\hline Moderate & $24(24.7)$ \\
\hline Minor & $2(2.1)$ \\
\hline Intubated ("breathing tube"for mechanical ventilation) & $37(38.1)$ \\
\hline Prior-year hospitalization with AWS, no. (\%) & 19 (19.6) \\
\hline Positive serum/urine alcohol level, ${ }^{\mathrm{a}}$ no. (\%) & $58(59.8)$ \\
\hline AWS was the primary reason for admission, no. (\%) & $5(5.2)$ \\
\hline \multicolumn{2}{|l|}{ Admitting service, no. (\%) } \\
\hline Medical ICU & $49(50.5)$ \\
\hline Trauma ICU & $24(24.7)$ \\
\hline Neurological ICU & $24(24.7)$ \\
\hline Admission ${ }^{b}$ CIWA-Ar assessment, no. (\%) & $54(55.7)$ \\
\hline \multicolumn{2}{|l|}{ Admission ${ }^{b}$ CIWA-Ar category, no. $(\%)^{c}$} \\
\hline Mild AWS (CIWA-Ar score $\leq 8)$ & $28(51.9)$ \\
\hline Moderate AWS (CIWA-Ar score 9-19) & $20(37.0)$ \\
\hline Severe AWS (CIWA-Ar score $\geq 20)$ & $6(11.1)$ \\
\hline Admission ${ }^{b}$ RASS assessment, no. (\%) & $91(93.8)$ \\
\hline \multicolumn{2}{|l|}{ Admission ${ }^{b}$ RASS category, no. $(\%)^{d}$} \\
\hline Oversedation (RASS score -3 to -5 ) & $34(37.4)$ \\
\hline Optimal sedation (RASS score -2 to 0 ) & $31(34.1)$ \\
\hline Undersedation (RASS score +1 to +4 ) & $26(28.6)$ \\
\hline
\end{tabular}

CIWA-Ar Clinical Institute Withdrawal Assessment for Alcohol-Revised, RASS Richmond Agitation-Sedation Scale

a Assessment completed within $24 \mathrm{~h}$ of hospital presentation

b Assessment completed within $24 \mathrm{~h}$ of ICU admission

c Denominator used to calculate percentages was the number of patients with a CIWA-Ar assessment $(n=54)$

d Denominator used to calculate percentages was the number of patients with a RASS assessment $(\mathrm{n}=91)$

across several patient demographic and clinical characteristics (Table 2). In unadjusted analyses, CIWA-Ar assessments were less common among patients who were intubated $(8 \%, \mathrm{n}=3 / 37)$, extremely ill $(29 \%, \mathrm{n}=10 / 34)$, or Black $(36 \%, n=4 / 11)$, and more common among
American Indian/Alaska Natives (91\%, $n=10 / 11)$, patients previously hospitalized with AWS (84\%, $\mathrm{n}=16 / 19)$, and patients with a positive serum/urine alcohol level $(65.5 \%, \mathrm{n}=38 / 58)$. After adjustment, only intubation status and race were significantly associated with CIWA-Ar assessment. Specifically, both intubation and Black race were associated with lower likelihood of CIWA-Ar monitoring than no intubation and White race, respectively (Table 2).

Of the 54 patients with CIWA-Ar assessments, the majority $(52 \%, \mathrm{n}=28 / 54)$ had scores indicating mild AWS (CIWA-Ar $\leq 8$ ) requiring no additional pharmacotherapy. However, in the broader subset of 91 patients $(94 \%)$ who had a RASS assessment within $24 \mathrm{~h}$ of ICU admission, a minority were considered optimally sedated ( $34 \%, n=31 / 9$, RASS -2 to 0$), 37 \%$ were considered oversedated ( $n=34 / 91$, RASS -3 to -5 ), and $29 \%$ were considered undersedated or agitated $(n=26 / 91$, RASS +1 to + 4) [8].

\section{Discussion}

In this sample of 97 ICU patients treated for AWS, nearly half (46\%) were not monitored with the CIWA-Ar despite a hospital protocol specifying its use. CIWA-Ar monitoring varied across patient characteristics and was completed less often for patients who were intubated or identified as Black. This is the first study to evaluate clinical use of the CIWA-Ar in ICU patients.

Inconsistent application of the CIWA-Ar in ICU patients raises questions about its utility in the ICU. Although a high-visibility trial demonstrated symptomtriggered therapy using the CIWA-Ar reduced overall benzodiazepine exposure and treatment duration for patients with uncomplicated AWS [4], the CIWA-Ar requires patients to be oriented and communicative $[2,3]$. Intubation (a mechanical obstruction to verbal communication) is a barrier to CIWA-Ar monitoring. Although use of the CIWA-Ar was appropriately deferred in all but 3 intubated patients in this study, AWS treatment monitoring is still warranted in the setting of intubation. The correct solution to this monitoring problem has not been identified.

This study has several limitations. It is the first to explore possible associations between patient characteristics and CIWA-Ar monitoring, thus a priori selection of potential confounders for the multivariable model was guided by limited literature. Significant results should be considered hypothesis-generating, especially given the small sample size. In particular, while the identified association between race and CIWA-Ar monitoring could reflect differences in care associated with racism, and/or biases and stigma associated with addiction [12-14], this association requires further exploration in larger samples 


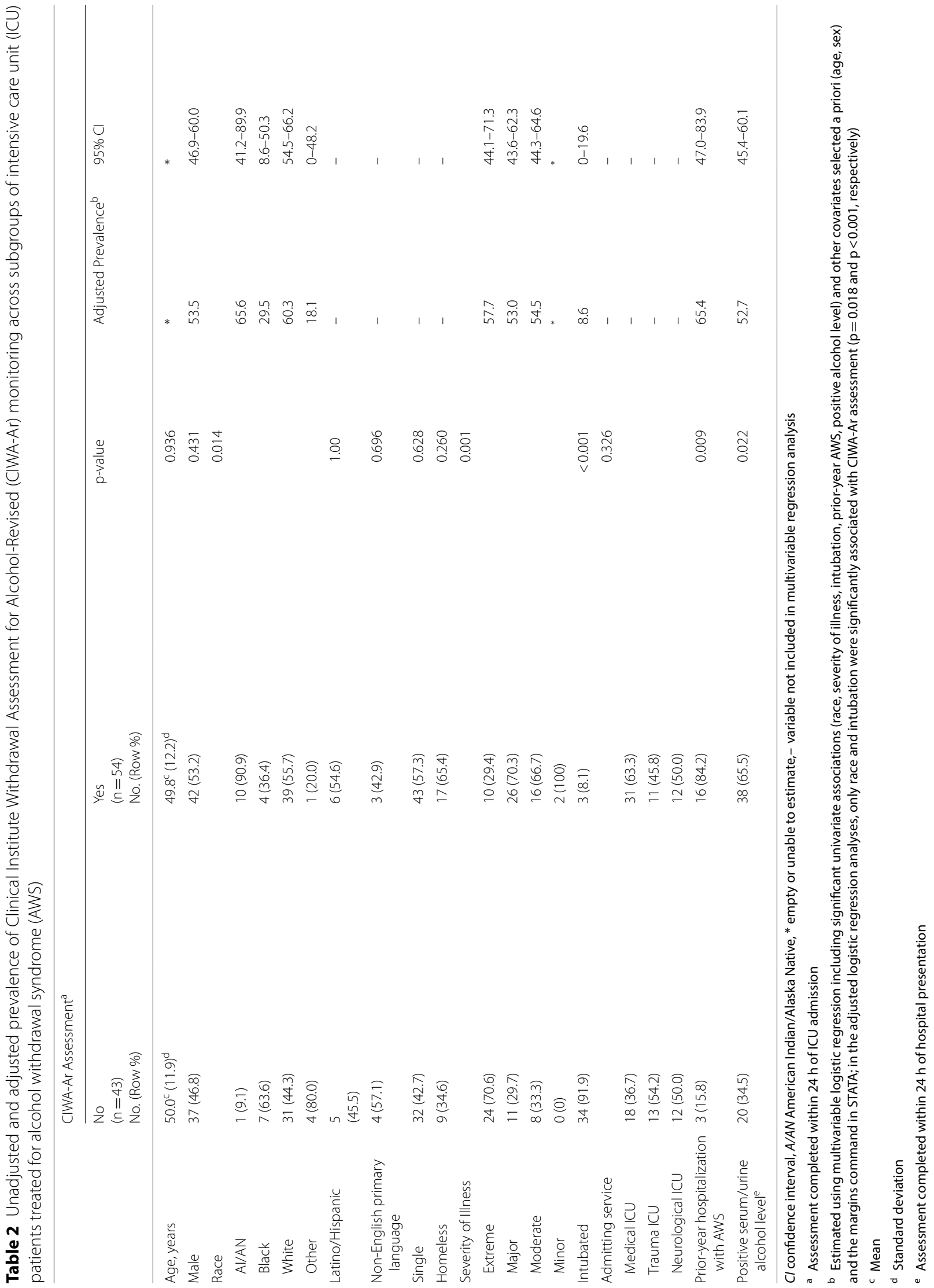


of ICU patients. Additionally, a majority of patients included in the study $(\mathrm{n}=92 / 97,95 \%)$ were admitted primarily for management of acute medical/surgical illnesses rather than AWS. Signs/symptoms associated with these other conditions may have confounded the results of CIWA-Ar assessments. This is a limitation, in this study and in clinical practice, as previous research also suggests $96-98.5 \%$ of patients experiencing AWS in hospital settings are admitted for other acute indications [9-11]. Despite the inherent limitations of this singlehospital study design, it has important strengths: this is the first naturalistic evaluation of CIWA-Ar monitoring in ICU settings, data were derived from systematic chart reviews, and the study sample was defined such that timing of AWS treatment onset was standardized.

Results of this study support the feasibility of the American Society of Addiction Medicine's recent suggestion that sedation measures such as the RASS be used, rather than the CIWA-Ar, to monitor AWS severity and response to treatment in ICU patients [2]. The RASS was completed in $94 \%$ of ICU patients with AWS in this study. Although never specifically evaluated/validated for management of AWS, the RASS has several strengths that make it potentially useful for AWS monitoring in ICUs: it is already widely used to support ICU care, it relies on provider assessment rather than patient interview, and it could identify both under- and over-treatment of AWS (i.e., bi-directionality). Future studies should assess the utility of the RASS for titrating AWS medications compared to other AWS severity scales that do not require patient self-report [15-23], emphasizing appropriate use in patients with wide-ranging characteristics to improve the quality of care for ICU patients with AWS.

\section{Abbreviations \\ AWS: Alcohol withdrawal syndrome; CIWA-Ar: Clinical Institute Withdrawal Assessment for Alcohol-Revised; ED: Emergency Department; ICD: Inter- national classification of diseases; ICU: Intensive care unit; RASS: Richmond Agitation-Sedation Scale; APR-DRG: All Patients Refined Diagnosis Related Groups.}

\section{Acknowledgements}

Not applicable.

\section{Authors' contributions}

TLS: Study design and analysis, data acquisition, results interpretation, drafting and editing the manuscript. SPG: Study design and analysis, drafting and editing the manuscript. SCK: Data acquisition and project management, drafting and editing the manuscript. SMC: Study design and analysis, data acquisition, results interpretation, drafting and editing the manuscript. KBS: Data acquisition, results interpretation, drafting and editing the manuscript. BM: Data acquisition, results interpretation, drafting and editing the manuscript. HS: Data acquisition, results interpretation, drafting and editing the manuscript. CLH: Study design and analysis, drafting and editing the manuscript. KAB: Study design and analysis, drafting and editing the manuscript. ECW: Study design and analysis, drafting and editing the manuscript. All authors read and approved the final manuscript.

\section{Funding}

This research was supported by the National Institutes of Health (i.e. K24AA022128), which had no role in designing the study, collection, analysis, and interpretation of data, nor writing the manuscript.

\section{Availability of data and materials}

We do not have permission to release our data, which was collected via patient chart review and could compromise individual privacy.

\section{Declarations}

Ethics approval and consent to participate

This study received approval with a waiver of consent from the University of Washington Institutional Review Board.

\section{Consent for publication}

Not applicable.

\section{Competing interests}

The authors declare that they have no competing interests.

\section{Author details}

${ }^{1}$ Seattle-Denver Center of Innovation (COIN), VA Puget Sound Health Care System, Seattle Division, 1660 South Columbian Way S-152, SeattleSeattle, WA 98108, USA. ${ }^{2}$ Division of Pulmonary, Critical Care, \& Sleep Medicine, University of Washington, Seattle, WA, USA. ${ }^{3}$ Division of Pulmonary, Critical Care, \& Sleep Medicine, Harborview Medical Center, Seattle, WA, USA. ${ }^{4}$ Department of Medicine, Harborview Medical Center, Seattle, WA, USA. ${ }^{5}$ University of Washington Internal Medicine Residency Program, Seattle, WA, USA. ${ }^{6}$ Department of Pharmacy Services, Harborview Medical Center, Seattle, WA, USA. ${ }^{7}$ Kaiser Permanente Washington Health Research Institute, Seattle, WA, USA.

Received: 25 September 2020 Accepted: 3 March 2021

Published online: 24 March 2021

\section{References}

1. Monte R, Rabunal R, Casariego E, Lopez-Agreda H, Mateos A, Pertega S. Analysis of the factors determining survival of alcoholic withdrawal syndrome patients in a general hospital. Alcohol Alcohol. 2010;45(2):151-8.

2. Wong J, Saver B, Scanlan JM, Gianutsos LP, Bhakta Y, Walsh J, Plawman A, Sapienza D, Rudolf V. The ASAM clinical practice guideline on alcohol withdrawal management. J Addict Med. 2020;14(3S Suppl 1):1-72.

3. Sullivan J, Sykora K, Schneiderman J, Naranjo C, Sellers E. Assessment of Alcohol Withdrawal: the revised clinical institute withdrawal assessment for alcohol scale (CIWA-Ar). Brit J Addict. 1989;84(11):1353-7.

4. Saitz R, Mayo-Smith MF, Roberts MS, Redmond HA, Bernard DR, Calkins DR. Individualized treatment for alcohol withdrawal A randomized double-blind controlled trial. JAMA. 1994;272(7):519-23.

5. Hecksel KA, Bostwick JM, Jaeger TM, Cha SS. Inappropriate use of symptom-triggered therapy for alcohol withdrawal in the general hospital. Mayo Clin Proc. 2008;83(3):274-9.

6. Eloma AS, Tucciarone JM, Hayes EM, Bronson BD. Evaluation of the appropriate use of a CIWA-Ar alcohol withdrawal protocol in the general hospital setting. Am J Drug Alcohol Abus. 2018;44(4):1-8.

7. Ely EW, Truman B, Shintani A, et al. Monitoring sedation status over time in ICU patients. JAMA. 2003;289(22):2983-91.

8. Devlin JW, Skrobik Y, Gélinas C, et al. Clinical practice guidelines for the prevention and management of pain, agitation/sedation, delirium, immobility, and sleep disruption in adult patients in the ICU. Crit Care Med. 2018;46(9):e825-73.

9. Foy A, Kay J. The incidence of alcohol-related problems and the risk of alcohol withdrawal in a general hospital population. Drug Alcohol Rev. 1995;14(1):49-54.

10. Maldonado JR, Sher Y, Ashouri JF, Hills-Evans K, Swendsen H, Lolak S, Miller AC. The "Prediction of Alcohol Withdrawal Severity Scale" (PAWSS): Systematic literature review and pilot study of a new scale for the prediction of complicated alcohol withdrawal syndrome. Alcohol. 2014;48(4):375-90. 
11. Maldonado JR, Sher Y, Das S, Hills-Evans K, Frenklach A, Lolak S, Talley $R$, Neri E. Prospective validation study of the prediction of alcohol withdrawal severity scale (PAWSS) in medically III inpatients: a new scale for the prediction of complicated alcohol withdrawal syndrome. Alcohol Alcohol. 2015;50(5):509-18.

12. Alsan M, Garrick O, Graziani G. Does diversity matter for health? experimental evidence from Oakland. Am Econ Rev. 2019;109(12):4071-111.

13. Largent EA. Public health, racism, and the lasting impact of hospital segregation. Public Health Rep. 2018;133(6):715-20.

14. Seear K. Addressing alcohol and other drug stigma: Where to next? Drug Alcohol Rev. 2020;2:109-13.

15. Sander W. Protocol for intervention and treatment of alcohol withdrawal. Axone. 1997;19(1):10-3.

16. Reoux JP, Oreskovich MR. A comparison of two versions of the clinical institute withdrawal assessment for alcohol: the CIWA-Ar and CIWA-AD. Am J Addict. 2006;15(1):85-93.

17. Beresford T, Anderson M, Pitts B, Learned B, Thumm B, Maravilla F, Emrick C, Taub J. The severity of ethanol withdrawal scale in scale-driven alcohol withdrawal treatment: a quality assurance study. Alcohol Treat Q. 2017;35(3):1-11.

18. Watling SM, Fleming C, Casey P, Yanos J. Nursing-based protocol for treatment of alcohol withdrawal in the intensive care unit. Am J Critical Care Official Publ Am Assoc Critical-care Nurses. 1995;4(1):66-70.
19. Rastegar DA, Applewhite D, Alvanzo AAH, Welsh C, Niessen T, Chen ES. Development and implementation of an alcohol withdrawal protocol using a 5-item scale, the Brief Alcohol Withdrawal Scale (BAWS). Subst Abus. 2017;38(4):394-400.

20. Lindner BK, Gilmore VT, Kruer RM, et al. Evaluation of the brief alcohol withdrawal scale protocol at an academic medical center. J Addict Med. 2019;13(5):379-84.

21. Rastegar DA, Jarrell AS, Chen ES. Implementation of a protocol using the 5-item brief alcohol withdrawal scale for treatment of severe alcohol withdrawal in intensive care units. J Intensive Care Med. 2020:088506662095276.

22. Littlefield AJ, Heavner MS, Eng CC, Cooper DA, Heavner JJ, Kurtz JM, Pisani MA. Correlation between mMINDS and CIWA-Ar scoring tools in patients with alcohol withdrawal syndrome. Am J Crit Care. 2018;27(4):280-6.

23. Heavner JJ, Akgün KM, Heavner MS, Eng CC, Drew M, Jackson P, Pritchard D, Honiden S. Implementation of an ICU-specific alcohol withdrawal syndrome management protocol reduces the need for mechanical ventilation. Pharmacother J Hum Pharmacol Drug Ther. 2018;38(7):701-13.

\section{Publisher's Note}

Springer Nature remains neutral with regard to jurisdictional claims in published maps and institutional affiliations.
Ready to submit your research? Choose BMC and benefit from:

- fast, convenient online submission

- thorough peer review by experienced researchers in your field

- rapid publication on acceptance

- support for research data, including large and complex data types

- gold Open Access which fosters wider collaboration and increased citations

- maximum visibility for your research: over 100M website views per year

At BMC, research is always in progress.

Learn more biomedcentral.com/submissions 